\title{
A AUDIÊNCIA DE CUSTÓDIA COMO DIREITO HUMANO FUNDAMENTAL À LUZ DAS GARANTIAS CONSTITUCIONAIS E INTERNACIONAIS
}

\author{
THE CUSTODY HEARING AS A FUNDAMENTAL HUMAN RIGHT IN THE \\ LIGHT OF CONSTITUTIONAL AND INTERNATIONAL GUARANTEES
}

\author{
${ }^{1}$ Ivonaldo Da Silva Mesquita \\ ${ }^{2}$ Natália Ila Veras Pereira
}

\section{RESUMO}

A presente pesquisa trata, por meio de pesquisa bibliográfica e documental, e com amparo na legislação constitucional, infraconstitucional e pactos internacionais, sobre o direito à Audiência de Custódia. Como ponto central da pesquisa, questiona-se qual o real significado da Audiência de Custódia, sua abrangência, características e amparo normativo, e ainda, procura-se expor os muitos debates contra e a favor de sua implantação no país. Objetiva-se demonstrar que o instituto é um meio capaz de combater à superlotação carcerária, de resguardar a dignidade da pessoa humana, de prevenir e identificar práticas de tortura, em suma, proporcionar um maior amparo à pessoa detida. A pesquisa é justificada devido à relevância e atualidade da matéria no cenário nacional, diante dos muitos debates e dos esforços de importantes instituições para que a Audiência de Custódia seja uma realidade no país. De forma que, pretende-se contribuir para uma melhor compreensão desse importante direito, que deve ser reconhecido e amparado como um direito humano fundamental, até então esquecido.

Palavras-chave: Direito constitucional, Direitos humanos, Direitos fundamentais, Dignidade da pessoa humana, Audiência de custódia

\begin{abstract}
This research deals, through bibliographic and documentary research, and support in constitutional law, infraconstitutional law and international agreements, on the right to Custody Hearing. As the central point of the research, it is questioned the real meaning of Custody Hearing, its scope, characteristics and regulatory support, and also seeks to expose the many debates against and in favor of its implementation in the country. The objective is to demonstrate that the Custody Hearing is a mean capable of facing prison overcrowding, to safeguard the dignity of the human person, to prevent and identify torture, in short, provide greater protection to the detainee. The research is justified by the relevance and timeliness of matter in the national scenario, in light of the many debates and efforts of institutions important for the Custody Hearing is a reality in the country. So, we intend to contribute to a better understanding of this important right that must be recognized and supported as a fundamental human right, hitherto forgotten.
\end{abstract}

Keywordss: Constitutional rights, Human rights, Fundamental rights, Dignity of the human person, Custody hearing

1Mestre em Direito Constitucional pela Universidade de Fortaleza - UNIFOR, Ceará, (Brasil). Professor do Curso de Direito da Faculdade - FAETE, Teresinha Piauí. E-mail: tutortreinamento@gmail.com

2Bacharelado em Direito pela Faculdade Mauricio de Nassau - ININASSAU, Bahia, (Brasil). Gerente Administrativa no Núcleo de Execuções Penais da Defensoria Pública do Estado do Piauí. E-mail: tutortreinamento@gmail.com 


\section{INTRODUÇÃO}

O presente trabalho analisa a Audiência de Custódia como um direito humano e fundamental, que encontra amparo tanto em pactos internacionais como na própria Constituição Federal Brasileira, abordando a sua conceituação, previsão normativa, finalidades, e demais aspectos jurídicos e sociais concernentes a temática.

É relevante frisar que o debate quanto à eficácia e necessidade das prisões, em especial das prisões provisórias, é tema que vem sendo potencializado diante dos muitos resultados negativos do cárcere e do afloramento do discurso garantista, onde cada vez mais vem se buscando alternativas que viabilizem a adoção de medidas alternativas para o acautelarmento da pessoa detida.

Tem-se como viés central da pesquisa, o seu real significado e o cenário brasileiro atual de discussão sobre a viabilidade e necessidade de implantação da Audiência de Custódia, expondo os pontos negativos e positivos que rondam a matéria, para só então se entender o papel do direito no amparo à esse direito humano fundamental até então esquecido.

A problemática gira em torno dos debates sobre as prisões e suas finalidades para o acautelamento estatal, objeto de diversas críticas por parte dos defensores dos direitos humanos, principalmente em um país onde as condições de encarceramento são bastante questionáveis à luz da dignidade da pessoa humana. Ademais, as diversas mudanças advindas com a nova ordem mundial de resguardo aos direitos humanos, aos poucos tem conseguido avanços nesse setor.

Ocorre que, a implantação desse direito fundamental tem encontrado resistência em alguns setores da sociedade, que focam principalmente na inviabilidade da implantação da Audiência de Custódia no país, tal posicionamento é justificado por motivos como falta de recursos e ausência de regulamentação interna da matéria. Alguns alegam ainda a sua desnecessidade, pregando que poucos dos objetivos almejados seriam alcançados, no qual não existiria impacto na redução de prisões provisórias, p.ex.

As hipóteses firmadas dizem respeito ao atual estado de transformação que passa os direitos humanos, na medida em que sua internacionalização vem se sobrepondo às fronteiras estatais com a relativização das soberanias, tudo em busca de uma proteção mais eficaz. Nesses moldes, a internacionalização de diversos direitos humanos estaria contribuindo para o reconhecimento e resguardo dos direitos no plano interno.

Sendo assim, a implantação da Audiência de Custódia é um direito humano fundamental que encontra amparo internacional e respaldo constitucional diante dos 
mecanismos de internalização de direitos humanos, portanto, deve ser como tal reconhecido e efetivado no plano interno, ressaltando-se até então a omissão do estado diante de tal garantia.

Ainda, a audiência de custódia é mais uma frente de combate à superlotação e desumanização que acomete as prisões. Levar acusados a presença de um juiz, é uma atitude capaz de abandonar a frieza da análise apenas de documentos, como hoje é a praxe processual de encaminhar apenas o auto de prisão em flagrante. Da mesma forma que essa conduta coloca em prática o que já vem previsto em lei, e que ainda é pouco observada, que é a aplicação das medidas cautelares diversas da prisão.

A pesquisa tem como objetivo principal identificar e analisar o quadro atual de debate para implantação da Audiência de Custódia no Brasil. Tem igualmente como objetivos, retratar o histórico das mudanças ocorridas no cenário internacional no que diz respeito à proteção dos direitos humanos, pesquisar os mecanismos de resguardo constitucional para a internacionalização desses direitos, expor os pontos positivos e negativos que estão sendo discutidos sobre a implantação e reconhecimento da Audiência de Custódia como direito humano e fundamental e, por fim, rebater os motivos que justificam a relutância para a sua implantação.

Tem-se como principal justificativa, a relevância da implantação da Audiência de Custódia no país como um meio de presença e amparo imediato do Estado à pessoa detida para proteção de seus direitos, constatada inicialmente pela experiência laboral de contato direto com a realidade prisional através da Defensoria Pública do Estado do Piauí.

Ainda, apesar de ter resguardo internacional e constitucional, muitos ainda são os desafios para que haja um amparo legal efetivo para sua efetivação, no qual, sem dúvida, o principal deles é mudar o entendimento permeado na sociedade de que o cárcere é a solução para a (in) segurança pública.

Tudo evidencia a relevância da pesquisa diante das sérias questões, causas e consequências, nos mais diversos ramos, sejam sociais, jurídicos ou políticos. Toda a temática é voltada para as transformações que vêm ocorrendo e sendo debatidas no cenário brasileiro, e em como o Direito Constitucional tem contribuído para uma proteção fundada na dignidade da pessoa humana.

A metodologia do trabalho é baseada em estudos doutrinários, legais e jurisprudenciais, com adoção de procedimentos técnicos de pesquisa bibliográfica, pesquisa documental. Em suma, trata-se de uma pesquisa descritiva e explicativa, tida como pesquisa básica ou pura. 
A parte inicial trata das noções gerais correlacionadas aos diversos aspectos que giram em torno do tema. E, por conseguinte, debatem-se as vantagens, desvantagens e atuais entraves para sua efetivação no país.

$\mathrm{Na}$ parte final busca-se traçar um paralelo entre o instituto e os seus debates atuais, discutindo, entre eles, a Ação Direta de Inconstitucionalidade n 5240/2015 que debate a inconstitucionalidade do diploma normativo que regulamentou a Audiência de Custódia no estado de São Paulo; o Projeto de Lei n ${ }^{\circ}$ 554/2011 que propõe alterar o Código de Processo Penal Brasileiro para prever expressamente o procedimento para sua realização; o Apoio do Conselho Nacional de Justiça que, em parceria com os Tribunais de Justiça dos Estados, tem implantado paulatinamente nas capitais dos estados da federação o procedimento necessário para que a Audiência de Custódia já possa ser uma realidade a ser experimentada no país.

\section{SOBRE A AUDIÊNCIA DE CUSTÓdIA: CONCEITO, CARACTERÍSTICAS E PREVISÃO NORMATIVA}

Diversas são as questões que rondam a denominada Audiência de Custódia, ou simplesmente, Audiência de Apresentação, termo esse menos utilizado. Para que se possa entender o real significado do direito à Audiência de Custódia, alguns dessas questões merecem apontamentos.

\subsection{Conceito e Características}

A chamada Audiência de Custódia, em linhas gerais, é o direito do acusado, em situação de flagrante, ser levado sem demora à presença de um juiz para que só então ele possa decidir sobre sua prisão. Objetiva-se que o acusado seja, em pouco tempo, apresentado à autoridade judicial, em uma audiência em que estarão presentes outras autoridades, como o representante do Ministério Público, o advogado do preso, ou na ausência deste, de um Defensor Público.

Durante a referida audiência, serão analisados diversos aspectos relacionados à prisão da pessoa acusada, principalmente no que diz respeito à legalidade, adequação ou mesmo necessidade de sua manutenção, além de se avaliar outras irregularidades, como ocorrência de maus tratos contra a pessoa presa. Nela, o acusado e as autoridades presentes ficam adstritos a aspectos alheios ao mérito do fato delituoso que futuramente será apurado, apenas focam na prisão em si e na pessoa do acusado. 
Em verdade, é um mecanismo de humanização, que visa o combate e prevenção à tortura e aos maus-tratos à pessoa presa, ao mesmo tempo em que serve de garantia de controle judicial sobre a necessidade e legalidade das prisões provisórias, já que há muito se busca encontrar um meio de prévio e célere para controle das mesmas, ou de reduzir a sua ocorrência, ou mesmo de expandir a aplicação de meios alternativos ao encarceramento.

Registra-se que, no Brasil, de acordo com o último senso penitenciário realizado pelo Conselho Nacional de Justiça $-\mathrm{CNJ}^{1}$, em 2014, havia 563.526 pessoas efetivamente presas, entre as quais $42 \%$ seriam de pessoas presas provisoriamente. $\mathrm{O}$ que rendeu ao país o quarto lugar entre os países com o maior contingente de pessoas presas e, se considerando também as prisões domiciliares e em regime aberto, o país ocuparia o terceiro lugar do mundo em que mais se acautela pessoas.

\subsection{Previsão Normativa}

A Audiência de Custódia é um direito previsto em vários países do mundo e em diversos diplomas internacionais de proteção aos direitos humanos, dentre entre, o conhecido e tão importante Pacto de São José da Costa. O Brasil, apesar de ser um país signatário do mencionado pacto, sua legislação processual ainda é omissa sobre a regulamentação da matéria, o que é razão de muitos debates, conforme se demonstra a seguir.

\subsubsection{Previsão na Convenção Americana de Direitos Humanos (Pacto de São José da Costa Rica) e demais Diplomas internacionais}

A Audiência de Custódia encontra previsão em diversos diplomas internacionais de salvaguarda dos direitos humanos, dentre eles a Convenção Americana de Direitos Humanos - CADH (também conhecida como Pacto de São José da Costa Rica) e Pacto Internacional de Direitos Civis e Políticos.

O Brasil aderiu a Convenção Americana de Direitos Humanos em 1992, tendo-a promulgado internamente por meio do Decreto $\mathrm{n}^{\circ} 678$ no mesmo ano $^{2}$. Conforme prevê o artigo 7.5 da mencionada Convenção:

7. 5. Toda pessoa detida ou retida deve ser conduzida, sem demora, à presença de um juiz ou outra autoridade autorizada pela lei a exercer funções judiciais e tem direito a ser julgada dentro de um prazo razoável ou a ser posta em liberdade, sem

\footnotetext{
${ }^{1}$ Dados divulgados pelo Conselho Nacional de Justiça. Disponível em: http://www.cnj.jus.br/sistema-carcerarioe-execucao-penal/audiencia-de-custodia/perguntas-frequentes. Acesso em: 18 de maio de 2015.

2 BRASIL. Decreto $\mathbf{n}^{\circ}$ 678, de 06 de novembro de 1992. Disponível em: http://www.planalto.gov.br/ccivil_03/decreto/ D0678.htm. Acesso em: 09 de abr. de 2015.
} 
prejuízo de que prossiga o processo. Sua liberdade pode ser condicionada a garantias que assegurem o seu comparecimento em juízo. ${ }^{3}$

Em que pese não ser um instituto vigente no país, é um direito reconhecido em diversos países do mundo. Alguns Estados membros do Sistema Interamericano de Proteção aos Direitos Humanos, já sofreram condenação na seara internacional, em decorrência do descumprimento do determinado no artigo 7.5 da Convenção.

Exemplo disso, em 24 de junho de 2004, a Corte Interamericana de Direitos Humanos, no Caso Acosta Calderón contra Equador, condenou o país por violação ao direito à Audiência de Custódia, isso porque no caso em comento, o Sr. Acosta Calderon foi detido, no entanto só foi apresentado perante um juiz depois de dois anos de sua prisão, na oportunidade a Corte ressaltou a importância da Audiência de Custódia, afirmando que:

\begin{abstract}
El artículo 7.5 de la Convención dispone que toda persona sometida a una detención tiene derecho a que una autoridad judicial revise dicha detención, sin demora, como medio de control idóneo para evitar las capturas arbitrarias e ilegales. El control judicial inmediato es una medida tendiente a evitar la arbitrariedad o ilegalidad de las detenciones, tomando en cuenta que en un Estado de derecho corresponde al juzgador garantizar los derechos del detenido, autorizar la adopción de medidas cautelares o de coerción, cuando sea estrictamente necesario, y procurar, en general, que se trate al inculpado de manera consecuente con la presunción de inocencia. ${ }^{4}$
\end{abstract}

Em precedente análogo, no Caso Bayarri contra Argentina $^{5}$, a Corte reconheceu que o Estado da Argentina havia violado o direito à Audiência de Custódia nos moldes reconhecidos na CADH, já que o Sr. Bayarri foi apresentado quase uma semana após o ato da detenção e, portanto, não satisfez o requisito exigido de prontamente ser apresentado perante a autoridade judiciária, conforme artigo 7.5 da Convenção Americana, consignando que o Estado não realizou um controle judicial efetivo do ato de detenção.

A CIDH ainda prevê outros direitos e garantias relacionados ao aqui debatido:

Art. $8^{\circ}$ - Garantias judiciais

1. Toda pessoa terá o direito de ser ouvida, com as devidas garantias e dentro de um prazo razoável, por um juiz ou Tribunal competente, independente e imparcial, estabelecido anteriormente por lei (...)

Art. 25 - Proteção judicial

1. Toda pessoa tem direito a um recurso simples e rápido ou a qualquer outro recurso efetivo, perante os juízes ou tribunais competentes, que a proteja contra atos que violem seus direitos fundamentais. ${ }^{6}$

\footnotetext{
${ }^{3}$ Convenção Americana de Direitos Humanos. Disponível em: http://www.cidh.oas.org/basicos/ portugues/c. Convencao_Americana.htm. Acesso em: 09 de abr. de 2015.

${ }^{4}$ Corte Interamericana de Direitos Humanos. Sentencia de 24 de junio de 2014 - Caso Acosta Calderón Vs. Ecuador. Disponível em: http://www.corteidh.or.cr/docs/casos/articulos/seriec_129_esp1.pdf. Acesso em: 25 de maio de 2015.

${ }^{5}$ Corte Interamerica de Direitos Humanos. Sentencia de 30 de octubre de 2008 - Caso Bayarri vs. Argentina. Disponível em: http://www.corteidh.or.cr/docs/casos/articulos/seriec_187_esp.doc. Acesso em: 25 de maio de 2015.

${ }^{6}$ Convenção Americana de Direitos Humanos. Disponível em: http://www.cidh.oas.org/basicos/ portugues/c. Convencao_Americana.htm. Acesso em: 09 de abr. de 2015.
} 
Da mesma forma, o Brasil aderiu em 1992 ao Pacto Internacional de Direitos Civis e Políticos - PIDCP, e o promulgou pelo Decreto $\mathrm{n}^{\circ} 592^{7}$, o diploma preleciona no artigo 9.3 que "qualquer pessoa presa ou encarcerada em virtude de infração penal deverá ser conduzida, sem demora, à presença do juiz ou de outra autoridade habilitada por lei a exercer funções judiciais" ${ }^{\circ}$. Assim, mais um diploma normativo internacional, internalizado pelo Brasil, prevê o direito à Audiência de Custódia.

Importante salientar aqui, a expressiva previsão constante no artigo $2^{\circ}$ da $\mathrm{CADH}$, que impõe a devida adequação do ordenamento jurídico interno dos países membros da Convenção, para cumprimento das obrigações assumidas, conforme previsto:

\begin{abstract}
Se o exercício dos direitos e liberdades mencionados no artigo no artigo 1 ainda não estiver garantido por disposições legislativas ou de outra natureza, os Estados-Partes comprometem-se a adotar, de acordo com as suas normas constitucionais e com as disposições desta Convenção, as medidas legislativas ou de outras natureza que forem necessárias para tornar efetivos tais direitos e liberdades. ${ }^{9}$
\end{abstract}

Desse modo, observa-se que o país ainda não se adequou as normas constantes nesses diplomas internacionais no que diz respeito à Audiência de Custódia, não nos termos ali prelecionados, no entanto, atualmente se observa um esforço por parte de alguns seguimentos da sociedade para sua implantação e devido amparo.

\title{
2.2.2 Ausência de previsão normativa interna infraconstitucional
}

Com o advento da Lei $\mathrm{n}^{\circ}$ 12.403/2011, a prisão no Brasil, ao menos no que ficou prelecionado, deveria ser a última medida cautelar a ser aplicada. A referida lei alterou o artigo 310 do Código de Processo Penal Brasileiro - CPPB e consignou que:

\footnotetext{
Art. 310. Ao receber o auto de prisão em flagrante, o juiz deverá fundamentadamente: (Redação dada pela Lei no 12.403 , de 2011).

I - relaxar a prisão ilegal; ou (Incluído pela Lei n ${ }^{\circ} 12.403$, de 2011).

II - converter a prisão em flagrante em preventiva, quando presentes os requisitos constantes do art. 312 deste Código, e se revelarem inadequadas ou insuficientes as medidas cautelares diversas da prisão; ou (Incluído pela Lei $\mathrm{n}^{\circ} 12.403$, de 2011).

III - conceder liberdade provisória, com ou sem fiança. (Incluído pela Lei ${ }^{\circ}{ }^{12.403}$, de 2011). ${ }^{10}$
}

7 BRASIL. Decreto $\mathbf{n}^{\circ}$ 592, de 06 de julho de 1992. Disponível em: http://www.planalto.gov.br/ccivil_03/decreto/1990-1994/D0592.htm. Acesso em: 09 de abr. de 1992.

8 Pacto Internacional de Direitos Civis e Políticos. Disponível em: http://www.planalto.gov.br/ccivil 03/decreto/ 1990-1994/D0592.htm. Acesso em 10 de ab. de 2015.

${ }^{\overline{9}}$ Convenção Americana de Direitos Humanos. Disponível em: http://www.cidh.oas.org/basicos/ portugues/c. Convencao_Americana.htm. Acesso em: 09 de abr. de 2015.

10 BRASIL. Código de Processo Penal Brasileiro. Disponível em: http://www.planalto.gov.br/ccivil_03/decreto-lei/del3689compilado.htm. Acesso em: 05 de maio de 2015. 
Desse modo, a lei fixou que a prisão cautelar apenas seria aplicada quando presentes requisitos que justificassem a prisão preventiva, e mesmo assim, quando inadequadas e insuficientes outras medidas acautelatórias diversas da prisão. Ocorre que, essa análise de cabimento é automatizada e distante da figura do detido, conforme procedimento previsto no CPPB, em seu artigo 306:

\begin{abstract}
Art. 306. A prisão de qualquer pessoa e o local onde se encontre serão comunicados imediatamente ao juiz competente, ao Ministério Público e à família do preso ou à pessoa por ele indicada. (Redação dada pela Lei $n^{\circ} 12.403$, de 2011).

§ 10 Em até 24 (vinte e quatro) horas após a realização da prisão, será encaminhado ao juiz competente o auto de prisão em flagrante e, caso o autuado não informe o nome de seu advogado, cópia integral para a Defensoria Pública. (Redação dada pela Lei no 12.403 , de 2011). (Grifou-se)
\end{abstract}

Nesses termos, a lei prevê a existência de comunicação imediata da ocorrência da prisão para o juiz, MP e família. Quanto ao auto de prisão de flagrante, este será encaminhado em até 24 horas ao juiz, e cópia será igualmente encaminhada à defensoria pública, caso o autuado não tenha informado o nome de seu advogado.

Conforme observado, a lei fixa que apenas o auto de prisão é que será encaminhado para o juiz, que decide sobre a prisão do acusado apenas com os elementos ali descritos, analisando a legalidade da prisão sem ter contato algum com o acusado do fato delituoso. O procedimento descrito em lei é motivo de diversas críticas, vez que a alteração legislativa não foi considerada eficaz para reduzir o número de prisões cautelares, nas palavras de Aury Lopes Jr. e Caio Paiva (2014, p. 13):

\footnotetext{
E o que verificamos na prática? Simples: que a lógica judicial permanece vinculada ao protagonismo da prisão, que a homologação do flagrante, longe de ser exceção, figura como regra no sistema processual penal brasileiro. Prova disso é que não houve a tão esperada redução do número de presos cautelares após a reforma de 2011. (grifos dos autores)
}

Nesse contexto, tem-se que, atualmente no Brasil, em matéria processual penal interna, inexiste previsão da apresentação do próprio detido perante a autoridade judiciária, de modo que o direito à Audiência de Custódia não encontra previsão normativa infraconstitucional, o que tem sido um verdadeiro entrave para que haja a adoção de procedimento competente para salvaguarda de tão importante direito.

\title{
2.2.3 Reconhecimento constitucional do instituto
}

Os direitos humanos reconhecidos no plano internacional, ao restarem positivados e reconhecidos na ordem interna de um Estado, acabam sendo taxados de direitos 
fundamentais, do que se presume que constituem o mesmo direito em essência, do que apenas se diferenciam pela amplitude do reconhecimento. Conforme bem reconhece Siqueira Jr. e Oliveira (2010, p. 24):

Os direitos humanos reconhecidos pelo Estado são denominados de direitos fundamentais, vez que via de regra são inseridos na norma fundamental do Estado, a Constituição. (...) Com o intuito de limitar o poder político estatal, os direitos humanos são incorporados nos textos constitucionais, apresentando-se como verdadeiras declarações de direitos do homem, que juntamente com outros direitos subjetivos públicos formam os chamados direitos fundamentais. Essa categoria de direito é na realidade uma limitação imposta aos poderes do Estado. Os direitos fundamentais são essenciais no Estado Democrático: formam a sua base, sendo inerentes aos direitos e liberdades individuais.

Daí se conclui que o direito à Audiência de Custódia é um direito humano, mas também é um direito fundamental, isso porque a $\mathrm{CF} / 88$ reconhece implicitamente essa garantia. Em que pese à ausência de previsão legal infraconstitucional no país, a Constituição Federal Brasileira - CF/88 preleciona um extenso rol de Direitos Fundamentais ao longo de seu texto, principalmente reunidos no artigo $5^{\circ}$. Conforme consta no artigo $5^{\circ}$, parágrafo $2^{\circ}$, da $\mathrm{CF} / 88$, “os direitos e garantias expressos nesta Constituição não excluem outros decorrentes do regime e dos princípios por eles adotados ou dos tratados internacionais em que a República Federativa do Brasil seja parte”.

Sobre o caráter exemplificativo de direitos fundamentais em decorrência do que consta no artigo $5^{\circ}$, parágrafo $2^{\circ}$ da $\mathrm{CF} / 88$, Manoel Gonçalves Ferreira Filho (2008, p. 100) explica que:

\begin{abstract}
Admite, portanto, a Constituição brasileira a existência de direitos fundamentais implícitos, como já o admitiam as anteriores. Estes hão de decorrer do "regime e dos princípios por ela adotados ou dos tratados internacionais em que a República seja parte". Tais direitos implícitos são direitos fundamentais por sua natureza. Podem ser induzidos ou deduzidos de outros que a Contituição explicita.
\end{abstract}

Destaca-se ainda o artigo $5^{\circ}$, parágrafo $1^{\circ}$ da $\mathrm{CF} / 88$, que confere aplicação imediata às normas definidoras dos direitos e garantias fundamentais. A CF/88 consigna, inclusive, a prevalência dos Direitos Humanos como um dos princípios norteadores nas relações internacionais, disposição expressa em seu artigo $4^{\circ}$, inciso II. Conforme ensina Flávia Piovesan (2012. p. 95) sobre a orientação do princípio da prevalência dos direitos humanos nas relações internacionais do Brasil:

\footnotetext{
Esse princípio invoca a abertura da ordem jurídica interna ao sistema internacional de proteção dos direitos humanos. A prevalência dos direitos humanos, como princípio a reger o Brasil no âmbito Internacional, não implica apenas o engajamento do País no processo de elaboração de normas vinculadas ao Direito Internacional dos Direitos Humanos, mas sim a busca da plena integração de tais regras na ordem jurídica interna brasileira. Implica, ademais, o compromisso de adotar uma posição política contrária aos Estados em que os direitos humanos sejam gravemente desrespeitados.
} 
Do que se conclui que, apesar da $\mathrm{CF} / 88$ não assegurar expressamente o direito à audiência de custódia, esta abre um leque de possibilidades para seu reconhecimento, ao firmar o entendimento no sentido de que direitos humanos reconhecidos em Tratados Internacionais em que o país faça parte serão de igual maneira salvaguardados.

Tal entendimento não poderia ser diferente, vez que essa categoria de direitos não são estáticos ou passíveis de serem reunidos em um rol fixo, em verdade, os direitos humanos constituem um grupo jurídico aberto, adaptável e ampliável à medida que a sociedade vai se transformando.

A CF/88, no artigo $5^{\circ}$, parágrafo $3^{\circ}$, ainda admite a possibilidade de que tratados e convenções internacionais sobre direitos humanos sejam equivalentes a emendas constitucionais, desde que aprovados com quórum qualificado, que seria a aprovação em cada Casa do Congresso Nacional, em dois turnos, por três quintos dos votos dos respectivos membros.

Assim, a CF/88 alinhou-se à finalidade constitucional-garantidora, visando garantir uma máxima eficácia aos direitos e garantias fundamentais ali previstos ou reconhecidos como tal, em especial da liberdade individual.

Resta consignar ainda que, apesar de toda a polêmica doutrinária que gira em torno da hierarquia dos tratados de direitos humanos, o Supremo Tribunal Federal - STF, no julgamento do Recurso Extraordinário $\mathrm{n}^{\circ} 466.343 / \mathrm{SP}{ }^{11}$, firmou entendimento de que a $\mathrm{CADH}$, por versar sobre direitos humanos e não ter sido aprovada no plano interno com o quórum qualificado exigido para que tratados internacionais, embora não tenham a mesma hierarquia de normas constitucionais, tem status normativo de supralegalidade, ou seja, estaria abaixo da Constituição, porém acima das demais normas infraconstitucionais.

Esse polêmico entendimento que reconhece a tese da supralegalidade, apesar das muitas críticas que o rondam, é ainda adotado no país de forma majoritária, o que acaba por gerar importantes consequências, como a validação do reconhecimento de que a CIDH estaria em posição hierarquicamente superior do Código de Processo Penal Brasileiro, e que embora neste não exista previsão acerca da Audiência de Custódia, aquele a prevê, merecendo ser como tal reconhecido.

11 STF- RE 466.343/SP, rel. Min. Cezar Peluso (22.11.2006). Disponível em: http://www.stf.jus.br/portal/ processo/ver ProcessoTexto.asp?id=2330845\&tipoApp=RTF . Acesso em: 18 de maio de 2015. 


\title{
3 A IMPLATAÇÃO DA AUDIÊNCIA DE CUSTÓDIA NO BRASIL
}

Pelo que se expõe até aqui, infere-se que, a exemplo de outros direitos humanos, o Estado ainda é omisso sobre a implantação efetiva da Audiência de Custódia. Sobre a necessidade de reconhecimento estatal e sobre a complexidade que envolve o amparo de muitos conteúdos básicos em matérias de direitos humanos em vista de sua efetividade prática, bem expõe Streck e Morais (2012, p.147):

\begin{abstract}
O que se percebe nesta seara é que muitos dos conteúdos básicos em muitos lugares sequer foi implementado ou muitos são sonegados e ao mesmo tempo precisamos dar conta de situações novas cada vez mais complexas, impondo-se ao jurista uma formação qualificada que lhe permita enfrentar competentemente os conflitos surgidos neste meio, sem esquecer o fundamental que são estratégias próprias ao Estado de Direito como Estado Democrático de Direito.
\end{abstract}

Assim, a complexidade que envolve a matéria, as muitas discussão sobre a (in) existência de amparo normativo da Audiência de Custódia no país, bem como as incertezas procedimentais e falta de posicionamento definitivo para sua implementação, fizeram com que muitos se posicionassem a favor ou contra o instituto, apontando suas vantagens e as desvantagens.

\subsection{As Vantagens da Implantação da Audiência de Custódia no Brasil}

Muitas são as razões que apontam favoravelmente para a implantação da Audiência de Custódia. Sendo a importância de tal procedimento inegável, conforme reconhecem Aury Lopes Jr. e Caio Paiva (2014, p.01):

São inúmeras as vantagens da implementação da audiência de custódia no Brasil, a começar pela mais básica: ajustar o processo penal brasileiro aos Tratados Internacionais de Direitos Humanos. Confia-se, também, à audiência de custódia a importante missão de reduzir o encarceramento em massa no país, porquanto através dela se promove um encontro do juiz com o preso, superando-se, desta forma, a "fronteira do papel" estabelecida no art. 306, $\S 1^{\circ}$, do CPP, que se satisfaz com o mero envio do auto de prisão em flagrante para o magistrado.

Segundo bem relata os autores, o instituto visa combater a superlotação carcerária, vez que, com a apresentação imediata do detido ao juiz, acredita-se que serão minimizadas as possibilidades de ocorrência de prisões ilegais ou mesmo ocorrência de prisões cautelares desnecessárias, tudo de uma forma mais imediata e célere. 
Somando-se a isso, a autoridade judiciária terá a oportunidade de analisar a situação do detido mais a fundo, haverá uma humanização do procedimento de apreciação sobre a necessidade de manutenção ou não de uma prisão cautelar, já que a análise do aprisionamento no país se pauta, inicialmente, em instrumentos unilateralmente fornecidos e realizados por um sistema inquisitórial averso a ampla defesa e contraditório.

Dessa forma, a Audiência de Custódia ainda é um meio de se garantir diversos princípios garantidos constitucionalmente, como o Princípio do Contraditório e da Ampla Defesa, previsto no Art. $5^{\circ}, \mathrm{LV}$ da $\mathrm{CF} / 88$.

A realização da audiência seria também um momento de se analisar com mais celeridade e eficácia a viabilidade da aplicação de uma medida cautelar diversa da prisão, já que, apesar dessas já serem previstas no ordenamento jurídico, são pouco aplicadas e muitos julgadores ainda se concentram na simples dicotomia liberdade provisória ou prisão preventiva.

Esse mecanismo de apresentação imediata também seria capaz de inibir atos como de tortura, maus-tratos, tratamento cruel e degradante despendidos contra os presos no ato de sua detenção, sejam esses realizados por agentes estatais ou mesmo por agressão por parte de outros presos que teve contado. Tais atos de violação a direitos fundamentais, apesar de ilegais, e dos muitos avanços no combate a essas práticas, ainda são recorrentes e uma realidade no país.

No entanto, os defensores da Audiência de Custódia, reconhecem o longo caminho a ser percorrido para que a implantação do instituto de fato alcance o esperado. Como bem lembra Aury Lopes Jr. e Alexandre de Morais Rosa, é evidente que o processo exige questões de adequação e tempo para uma implementação efetiva, nas palavras dos autores:
Aliás, a iniciativa reconhece a necessidade de evolução paulatina, partindo das seguintes premissas: “a) as apresentações dos autuados têm que ser ininterruptas (inclusive aos sábados, domingos, feriados, e recesso), b) deve haver estrutura séria e factível, facilitada pelo executivo, em condições de oferecer opções reais e concretas ao encarceramento provisório, c) o monitoramento constante e permanente dos resultados da experiência é condição essencial para corrigir eventuais desvios da experiência que se estará realizando, em tempo real e d) necessidade de prévia capacitação conceitual e instrumental de todos os envolvidos com a novel rotina processual garantista.

Nesse viés, não está se afirmando que o caminho para a realização da Audiência de Custódia seja simples, pelo contrário, requer um esforço conjunto de todos os autores envolvidos. No entanto, como bem pregam os seus defensores, é uma prática que pode ser 
realizada, ainda mais quando se vislumbra que os benefícios em sede de resguardo de direitos como integridade física, contraditório e ampla defesa.

\title{
3.2 As Desvantagens e Entraves para a Implantação da Audiência de Custódia no Brasil
}

No entanto, há quem seja contra a implantação da Audiência de Custódia, esse posicionamento é quase sempre embasado no que eles chamam de análise de custo e benefício, vez que pregam que o benefício seria muito baixo e que os resultados almejados não seriam alcançados como se espera, além de acreditarem que a pouca estrutura material seria potencializada, sem ganhos efetivos para a defesa.

Nesses termos, desacreditando do instituto e apontado que o elevado número de prisões não decorre da cultura do encarceramento ou mesmo de falhas nas técnicas procedimentais aplicadas, mas de diversas questões sociais que fazem com que a criminalidade no país seja elevada, as palavras de Cassiolato (2014, p. 01) versam que:

\begin{abstract}
Os números de nossa população carcerária e, dentro deles, a quantidade de presos provisórios, são realmente alarmantes. Esses números, sob minha visão, e salvo melhor juízo, decorrem muito mais de questões sociais e civilizatórias que enfrentamos atualmente (desigualdade social, aumento de crimes violentos, dificuldades de se coibir minimamente o tráfico de drogas, baixa escolaridade, falta de oportunidades profissionais, dentre outras) e de uma cultura de punição e vingança que parecem permear a sociedade (especialmente os meios de comunicação) que de certo modo acabam refletidas na atuação da polícia, do Ministério Público e da Magistratura. Não decorrem de falta de instrumentos processuais ou de falhas técnicas na aplicação jurisdicional deles. (Grifou-se)
\end{abstract}

Na visão de Barbosa (2015, p.01), com estudo aprofundado de casos já julgados pela Corte Interamericana de Direitos Humanos sobre a audiência de custódia, o autor explica quão profundo é o tema, diante do que ficou conhecido como laberling approach, ou "etiquetamento social", conforme bem ressalta:

Em outras palavras, a audiência de custódia é reflexo de uma política com discurso humanista, mas com manutenção da prática do labeling approach, pois de nada adianta o juiz ver ou "olhar no olho" do conduzido, se tem uma mentalidade de entiquetamento. A capacitação deveria ultrapassar a esfera da forma, do procedimento, e alcançar uma política minimalista de alterações estruturais com vistas à expansão da liberdade, aumentando as ferramentas para a manutenção da presunção de inocência, o que também é previsto no art. 8, item 2 da Convenção Americana de Direitos Humanos.

Como adverte o autor, de pouco adianta implantar a Audiência de Custódia se a mentalidade que gira em torno do encarceramento continuar a mesma e não se expandir ferramentas para resguardo da presunção de inocência, se assim não for, em nada diminuirá a realidade das prisões provisórias no país. O citado autor, ainda critica, de modo mais incisivo 
e com duras palavras, a falta de aprofundamento e estudo para que se entenda realmente o que significa a Audiência de Custódia:

(...) não houve um estudo sério sobre o que significa realmente a audiência de custódia. Não há nenhum estudo de capacitação sobre a compreensão do sistema internacional de proteção dos direitos humanos. Não há sequer, no Brasil, tradição em aplicação dos casos já julgados pela Corte IDH. É o sistema político do populismo penal de empoderamento do poder pelo poder, e não do poder pelo saber.

Sobre a polêmica que gira em torno do instituto, recentemente Guilherme de Sousa Nucci (2015, p.01), em artigo intitulado Os mitos da audiência de custódia, sintetizou uma gama de impressões pessoais sobre a polêmica instaurada, dispondo que:

Em suma: a) durante 23 anos, o texto da Convenção Americana sobre Direitos Humanos é o mesmo; somente agora, alguns descobriram que o Brasil o descumpre seguidamente; b) se é um direito humano fundamental, em todos os lugares onde não há audiência de custódia, os flagrantes devem ser imediatamente relaxados, pouco importando o caso concreto; c) se juízes precisam conversar com o réu para dar-lhe algum benefício, devemos transportar o interrogatório novamente para o início da ação penal; d) o projeto-piloto em S. Paulo (é interessante um experimento com direito humano fundamental indisponível...) vale-se do DIPO (Departamento de Inquéritos Policiais), onde os juízes são designados e removíveis a qualquer tempo; e) o sistema no Brasil não consegue transportar réus para as audiências, mas certamente haverá um imenso número de agentes (policiais?) para levá-los todos os dias à frente do juiz; f) a audiência de custódia, se tão importante, deveria estender- se ao Tribunal, para que também o desembargador/ministro possa conversar com o réu e sensibilizar-se; g) se a avaliação da autoridade policial não vale nada, visto que o preso precisa ir à frente do juiz, o destino dos delegados vai mudar completamente; passarão a sair às ruas para investigar e, prendendo, leva-se direto ao juiz; o auto de prisão em flagrante é inútil; h) os defensores, hoje, da audiência de custódia, como um direito fundamental, demoraram a acordar para isso (apenas 23 anos); mas já que o fizeram e estão despertos, convém levar logo ao STJ e ao STF a questão, por meio do habeas corpus para padronizar para todo o Brasil se sim ou se não a audiência de custódia; h) não há essa previsão no CPP; o STF tem a tendência de equiparar tratados a lei federal; de todo modo, mesmo que se considere a referida Convenção acima de qualquer lei, segundo nos parece, quem deve legislar sobre o procedimento nacional a ser adotado para a audiência de custódia é o Poder Legislativo e não o $\mathrm{CNJ}$, nem qualquer Tribunal Regional ou Estadual. A isto se chama legalidade, que vem sendo vilipendiada por um número excessivo de portarias, resoluções, provimentos e similares, originários dos mais diversos órgãos, sem o menor apego à função do legislador em matéria de direito criminal. Enfim, o mito dessa audiência é que ela é essencial para tirar presos provisórios do seu calvário.

Conforme pode se constatar, o autor se refere à audiência como um mito, um procedimento muito aquém do esperado, e acaba concluindo que:

De minha parte, continuarei a ler atentamente as peças escritas de habeas corpus e soltar quem considero merecer, seja pela ilegalidade da prisão, seja porque faz jus à liberdade provisória. E se for esta a vontade do STF, ouvirei sem problema o preso, mas continuarei mantendo a prisão cautelar ou concedendo liberdade provisória, de acordo com a lei - e não com lamúria de pessoa detida, por vezes, autora de crime grave. 
O relatado pelo autor reflete o sentimento de muitos julgadores nesse momento, que acreditam que ouvir ou não o acusado em pouco ou nada muda a análise que já vem sendo feita sobre a legalidade ou necessidade de manutenção de prisão cautelar.

Outro ponto de polêmica, diz respeito ao entendimento de que, se o Brasil não adota o procedimento da Audiência de Custódia previsto na CIHD, estaria em situação de direta violação ao seu artigo 7.5, e igualmente sujeito a sofrer condenações nos moldes de precedentes já proferidos no Sistema Interamericano de Direitos Humanos. Ou não, explica- se, a previsão constante no pacto diz respeito à apresentação a uma "autoridade judicial" e não jurisdicional, e no Brasil, essa autoridade judicial exigida poderia estar sendo representada pelo delegado de polícia, que no país é um cargo privativo de bachareis em direito, o que renderia ao país um alinhamento ao previsto. Tese essa bastante discutível, porém insuficiente para os reclames exigidos pelos moldes da garantia do contraditório e da ampla defesa.

Conforme pode ser observado, muitas são as controvérsias em torno da matéria, alguns pregam os muitos benefícios de sua implantação, enquanto outros acreditam que poucos serão os avanços na matéria.

\section{DEBATES ATUAIS}

Apesar das incertezas que rondam a temática e do peso dos argumentos favoráveis e contrários ao instituto, algumas medidas já estão sendo adotadas para que se tenha uma pacificação da matéria, dentre tais medidas, se destacam a Ação Direta de Inconstitucionalidade $\mathrm{n}^{\circ} 5240 / 2015$ e o Projeto de Lei ${ }^{\circ}$ 554/2011. Além, dessas questões, o apoio do Conselho Nacional de Justiça e de Tribunais de Justiça de alguns estados, tem sido peça chave para que a Audiência de Custódia já possa ser uma realidade no país. Sobre esses debates, maiores detalhes merecem destaquem.

\subsection{Ação Direta de Inconstitucionalidade (ADI) $n^{\circ}$ 5.240/2015}

A Ação Direta de Inconstitucionalidade - ADI n 5.240 de $2015^{12}$, de relatoria do Ministro Luiz Fux, foi proposta pela Associação de Delegados de Polícia do Brasil ADEPOL - Brasil, visando o reconhecimento da inconstitucionalidade do Provimento Conjunto $\mathrm{n}^{\circ}$ 03/2015, intituído entre a Presidência e Corregedoria Geral do Tribunal de

12 Andamento processual - ADI 5.240/2015. Disponível em: http://www.stf.jus.br/portal/processo/ver ProcessoAndamento.asp?incidente $=4711319$. Acesso em: 22 de julho de 2015. 
Justiça do Estado de São Paulo, que prescreveu normas para os integrantes do judiciário, ministério público, defensoria pública e para os próprios delegados, regularizando o procedimento de apresentação do acusado em situação de flagrante no prazo de até 24 horas da prisão, ou seja, o provimento instituiu a audiência de custódia no estado.

A ADEPOL-Brasil alega que o referido provimento é uma inovação normativa que contraria preceitos constitucionais, afirma que somente por meio de lei federal, de competência do Congresso Nacional, a audiência de custódia poderia ter sido estabelecida no estado e que um provimento autônomo não seria o meio adequado para tanto, isso porque é de competência federal legislar sobre matéria de direito processual. O provimento ainda seria contrário ao princípio da legalidade e da Separação de Poderes.

A última movimentação processual na mencionada ação constitucional, data de 16 de julho de 2015, refere-se ao requerimento da Defensoria Pública do Espírito Santo, no qual se pleiteia habilitação na ADI ${ }^{\circ} 5.240 / 2015$ como amicus curie ${ }^{13}$, requerendo ainda que lhe fosse franqueada ampla manifestação no feito. A Defensoria Pública alegou que a matéria teria pertinência direta no exercício de suas funções desempenhadas no respectivo estado, já que no Espírito Santo a Audiência de Custódia igualmente foi implantada por meio de provimento e em moldes parecidos com o do Estado de São Paulo.

Como pôde ser observado, a ação é permeada de controvérsias, envolvendo importantes instituições do país, como a Defensoria Pública Estadual e a Associação de Delegados de Polícia. Aguarda-se agora um posicionamento da Suprema Corte para julgamento e possível pacificação da matéria.

\subsection{O Projeto de Lei $n^{0} 554 / 2011$}

O Projeto de Lei $\mathrm{n}^{\circ} 554 / 2011^{14}$, que tem por autor o senador Antônio Carlos Valadares, visa alterar o artigo 306, parágrafo $1^{\circ}$ do CPPB, para que possa prever a obrigatoriedade da realização da Audiência de Custódia no direito brasileiro, com a seguinte redação seguindo em votação:

\footnotetext{
“Art. 306.

$\S 1^{\circ}$ No prazo máximo de vinte e quatro horas após a prisão em flagrante, o preso será conduzido à presença do Juiz para ser ouvido, com vistas às medidas previstas no art. 310 e para que se verifique se estão sendo
}

\footnotetext{
${ }^{13}$ Requerimento da Defensoria Pública do Estado do Espírito Santo para ingresso na ADI No 5.240/2015 como amicus curie. Disponível em: http://emporiododireito.com.br/wp-content/uploads/ 2015/07/\%C3\%ADntegradaPeti\%C3\%A7\%C3\%A3o.pdf. Acesso em: 21 de jul. de 2015.

14 BRASIL. Projeto de Lei do Senado n ${ }^{\circ}$ 554/2011. Disponível em: http://www.senado.gov.br/ atividade/materia/detalhes.asp?p_cod_mate=102115. Acesso em: 12 de maio de 2015.
} 


\begin{abstract}
respeitados seus direitos fundamentais, devendo a autoridade judicial tomar as medidas cabíveis para preservá-los e para apurar eventual violação.

$\S 2^{\circ} \mathrm{Na}$ audiência de custódia de que trata o parágrafo $1^{\circ}$, o Juiz ouvirá o Ministério Público, que poderá, caso entenda necessária, requerer a prisão preventiva ou outra medida cautelar alternativa à prisão, em seguida ouvirá o preso e, após manifestação da defesa técnica, decidirá fundamentadamente, nos termos do art. 310.

$\S 3^{\circ}$ A oitiva a que se refere o parágrafo anterior será registrada em autos apartados, não poderá ser utilizada como meio de prova contra o depoente e versará, exclusivamente, sobre a legalidade e necessidade da prisão; a prevenção da ocorrência de tortura ou de maus-tratos; e os direitos assegurados ao preso e ao acusado.

$\S 4^{\circ} \mathrm{A}$ apresentação do preso em juízo deverá ser acompanhada do auto de prisão em flagrante e da nota de culpa que lhe foi entregue, mediante recibo, assinada pelo Delegado de Polícia, com o motivo da prisão, o nome do condutor e os nomes das testemunhas.

$\S 5^{\circ}$ A oitiva do preso em juízo sempre se dará na presença de seu advogado, ou, se não o tiver ou não o indicar, na de Defensor Público, e na do membro do Ministério Público, que poderá inquirir o preso sobre os temas previstos no parágrafo $3^{\circ}$, bem como se manifestar previamente à decisão judicial de que trata o art. 310 deste Código."
\end{abstract}

Conforme apresentado nas justificativas da proposta, objetivou-se que fosse determinado o prazo de 24 horas para a apresentação da pessoa presa à autoridade judicial, a fim de que seja resguardada sua integridade não só física, mas também a psíquica.

Ainda, salienta-se que, como nos moldes constantes no projeto de lei, na Audiência de Custódia se analisará somente aspectos que rondam a legalidade e necessidade da prisão, bem como a ocorrência de tortura ou de maus-tratos praticados durante a custódia estatal, visando assegurar os direitos do preso e do acusado. Não será debatido o mérito do fato que será apurado e o que ocorrer durante o procedimento, não poderá ser usado como meio de prova num futuro processo.

Tercendo comentário sobre os artigos propostos na PL 554/2011, Fauzi Choukr (2015, p.01), em artigo intitulado A denominada "audiência de custódia”, afirma que:

\begin{abstract}
Ainda que o §1. Sugerido apresente-se, a rigor, desnecessário visto que as obrigações ali elencadas estão presentes na própria Constituição da República e na estrutura das cautelares pessoais em vigor, pode-se aplaudir ao menos a finalidade didática desse dispositivo, assim como o contraditório estabelcido no §2. o que seria redundante não fosse a histórica vocação para o modelo inquisitivo de processo. Das novas providências estabelecidas, aquela constante no § 3. I que surge como de grande valia prática vez uqe estabelece os limites da legalidade e da forma da oitiva, deixando claro que se trata de depoimento sem finalidade para o mérito da ação de conhecimento, complementado pelas disposições formais que se seguem.
\end{abstract}

O Projeto ressalta a necessidade de se cumprir o determinado na CIDH e no PIDCP, instrumentos internacionais de resguardo de direitos humanos aos quais o Brasil é signatário e que preveem o direito à Audiência de Custódia. Ainda, faz referência à prática mundial que está indo nesse sentido, em que países como a Alemanha, em que há a 
determinação de que a pessoa presa seja apresentada as autoridades competentes no dia seguinte a sua prisão.

É, portanto, visando adequação do ordenamento jurídico brasileiro às normativas internacionais de direitos humanos, que o projeto foi apresentado, vez que não há previsão interna infraconstitucional expressa acerca do procedimento para o resguardo do direito de apresentação do preso à autoridade judiciária.

O projeto se encontra em fase de tramitação regular e até o mês de julho de 2015, o projeto de lei estava na Comissão de Constituição, Justiça e Cidadania - CCJ, incluída em pauta para reunião ${ }^{15}$.

\subsection{Apoio do Conselho Nacional de Justiça}

Conselho Nacional de Justiça - CNJ não tem medido esforços para que a Audiência de Custódia seja implantada no país. De acordo com site oficial do conselho ${ }^{16}$, em fevereiro de 2015, o CNJ, juntamente com o Ministério da Justiça e o Tribunal de Justiça do Estado de São Paulo, lançou o Projeto Audiência de Custódia. O projeto visa à rápida apresentação do preso em situação de flagrante a um juiz, ainda, o projeto prevê a estruturação de centrais de alternativas penais, centrais de monitoramento eletrônico, centrais de serviços e assistência social e câmaras de mediação penal.

O Conselho objetiva expandir o projeto para os demais estados da federal, e para isso, tem realizado uma série de visitas aos mais diversos Tribunais de Justiça dos Estados, promovendo o debate e discutindo a viabilidade da implantação do projeto. O CNJ prega que a Audiência de Custódia deve ser regra nos Tribunais dos Estados, tudo para que se cumpra as normas de Direitos Humanos e as garantias constitucionais das pessoas presas constantes nos diplomas normativos internacionais no qual o Brasil manifestou adesão.

O fluxograma abaixo do Projeto Audiência de Custódia detalha mais precisamente como será o procedimento a ser adotado e que está sendo proposto pelo CNJ:

\footnotetext{
15 Tramitação do Projeto de Lei do Senado n 554/2011. Disponível em: http://www.senado.gov.br/ atividade/materia/detalhes.asp?p_cod mate $=102115$. Acesso em: 21 de julho de 2015 .

${ }^{16}$ Conselho Nacional de Justiça. Audiência de Custódia. Disponível em: http://www.cnj.jus.br/ sistemacarcerario-e-execucao-penal/audiencia-de-custodia. Acesso em: 18 de maio de 2015 .
} 


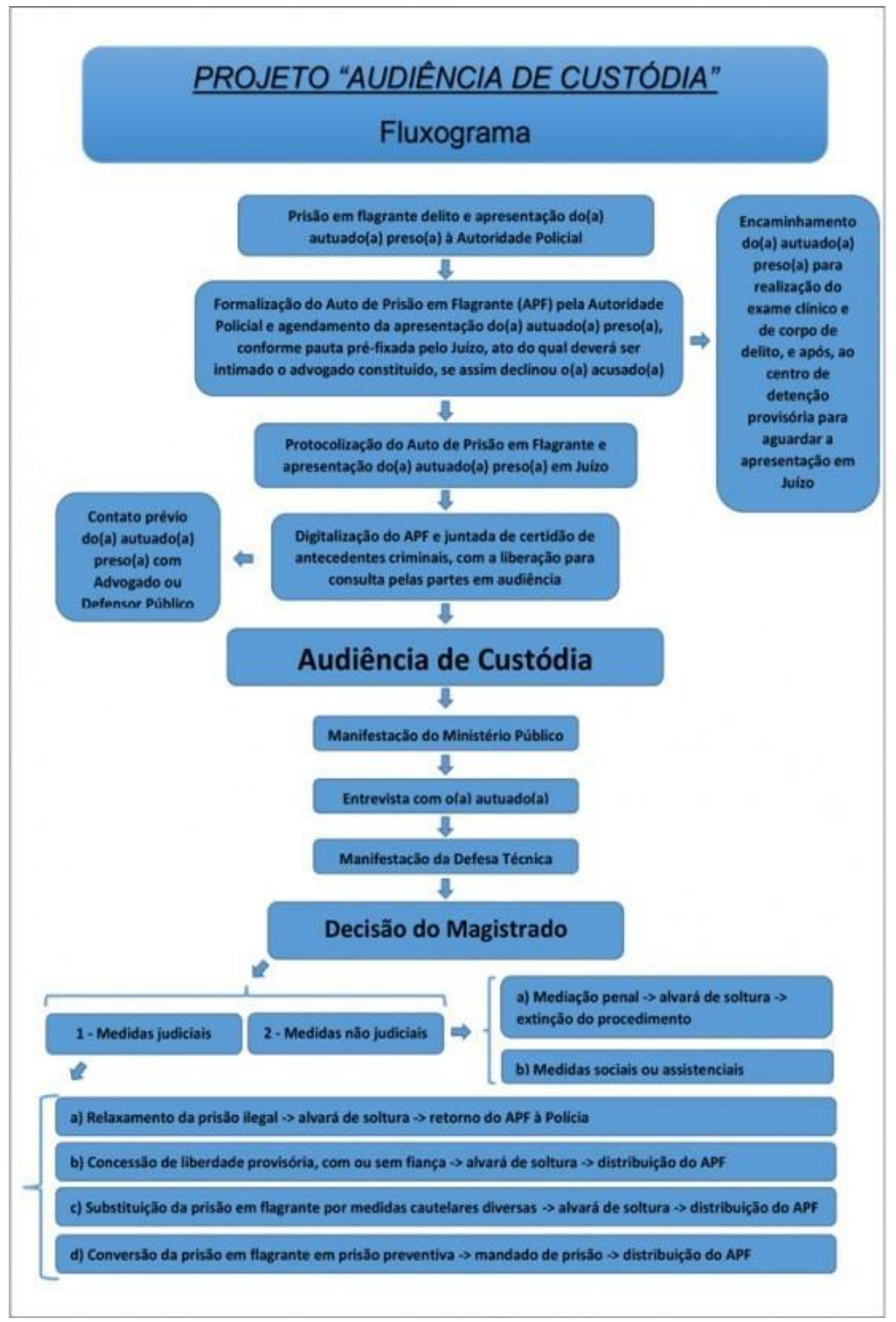

Figura 1: Fluxograma do Projeto Audiência de Custódia

Fonte: Conselho Nacional de Justiça - CNJ

Como pode ser observado pelo fluxograma, apesar de não existir lei no plano interno vigente o procedimento, o Projeto dita como serão os ditames a serem adotados. Dentro da proposta se destaca a possibilidade de adoção de medidas chamadas de judiciais, 
que basicamente são as medidas prelecionadas no artigo 310 do CPPB; e as medidas chamadas de não-judiciais, que consistem numa espécie de mediação penal, com a extinção do procedimento, ou na aplicação de medidas sociais ou assistenciais, estas medidas são inovações louváveis.

Apesar da iniciativa e os esforços despendidos pelo CNJ junto aos diversos Tribunais de Justiça dos Estados objetivando a implantação da audiência de custódia, o orgão tem sido alvo de muitas críticas e ataques, principalmente no que diz respeito a sua incompetência para tal feito, alega-se que há uma extrapolação de funções.

Em contrapartida da força do argumento exposto, fato é que em estados como São Paulo e Espírito Santo, as Audiências de Custodia já vêm ocorrendo com sucesso, à experiência tem se mostrado proveitosa nos moldes do projeto proposto pelo Conselho.

O Estado do Piauí, seguindo o movimento de aderência de outros estados da Federação ao projeto, em junho de 2015, foi firmando um Termo de Cooperação ${ }^{17}$ entre o Tribunal de Justiça do Estado do Piauí, a Corregedoria Geral de Justiça do Estado do Piauí, a Procuradoria Geral de Justiça do Estado do Piauí, a Defensoria Pública do Estado do Piauí, o Governo do Estado do Piauí, a Secretaria Estadual de Justiça e dos Direitos Humanos e a Secretaria de Segurança Pública, que objetivou a implantação de modo experimental de Audiência de Custódia na cidade de Teresina, capital do estado do Piauí.

No mesmo mês, o Tribunal de Justiça do Estado do Piauí publicou o Provimento Conjunto $\mathrm{n}^{\circ} 03 / 2015^{18}$, com republicação por incorreção em 21 de julho de 2015, que instituiu, em caráter experimental, o Projeto Plantão de Audiência de Custódia, no âmbito do Poder Judiciário do Estado do Piauí. O projeto prevê a realização da Audiência de Custódia na Comarca de Teresina diariamente, de segunda a sexta-feira, das 8 às 14 horas.

O provimento destoa em alguns pontos da essência do projeto original do $\mathrm{CNJ}$, mas já constitui um avanço digno de nota. O provimento entrará em vigor em 20 de agosto de 2015, e, por conseguinte, a primeira Audiência de Custódia no estado está marcada para ocorrer no final do mês de agosto.

\section{CONSIDERAÇÕES FINAIS}

Passados mais de 20 anos da internalização de diversos direitos humanos previstos em importantes instrumentos internacionais como a $\mathrm{CADH}$, e ainda diante do atual

\footnotetext{
${ }^{17}$ Diário Oficial do Estado do Piauí de 23 de junho de 2015. Disponível em: http://www.diariooficial.pi. gov.br/diario/201506/DIARIO23_e1a4309df1.pdf. Acesso em: 27 de julho de 2015.

${ }^{18}$ Diário Oficial de Justiça do Estado do Piauí de 21 de julho de 2015. Disponível em: http://www.tjpi. jus.br/site/uploads/diario/dj150721.pdf . Acesso em: 27 de julho de 2015.
} 
entendimento de sua supralegalidade ou equiparação a normas constitucionais, o cenário atual ainda é de omissão e desrespeito por muitos dos direitos ali reconhecidos, dentre eles a tão debatida Audiência de Custódia.

O problema aqui detectado não aparenta ser de ausência de previsão de normatividade, mas sim de vontade de resguardo de tão importante direito. A mentalidade do encarceramento é enraizada no seio da sociedade brasileira e vista como a solução para insegurança pública que assola o país. Há muito se sabe de todas as mazelas inerentes a essa medida minimalista de punição, onde muito se prende, pouco se combate, pouco se ressocializa, pouco se humaniza, porque não dizer, muito se desumaniza e pouco resolve.

Em meio a todo o esquecimento e marginalização do cárcere, resguardar a oportunidade de a pessoa em situação de flagrante ser prontamente levada perante as autoridades que decidirão, na sua presença, sobre seu destino, parece ser o mínimo a ser feito e garantido, já que não raro muitas são detidas e só apenas meses ou anos depois, são postas diante de um juiz, o que é motivo de muita revolta para essas pessoas.

Interessante ressaltar aqui, o conhecimento público e notório, de que apesar dos avanços no campo de assistencial judiciária à pessoa presa, muitos ainda permanecem detidos longos períodos sem ter tido contato direito e pessoal com advogado ou defensor público, que dirá com o juiz, se esse juízo de incerteza não é violação de direitos salutares como ampla defesa, não se sabe precisar o que seja então.

O peso de argumentos como o de falta de estrutura do Poder Judiciário, ou da desnecessidade de sua realização por se afirmar que os juízes não deixarão de manter a prisão por apenas ter contato com a pessoa do preso, ou que existe inconstitucionalidade de diplomas que a instituem, ou ainda, que existe usurpação de funções por alguns orgãos, parecem não serem suficientes diante dos benefícios que sua efetivação pode proporcionar e quando se encara a Audiência de Custódia como um direito já consagrado no plano externo e até mesmo reconhecido internamente, como demonstrado no presente trabalho.

Claramente, para que isso aconteça, é necessária uma mudança de paradigmas, um estudo mais aprofundado e a disponibilização de aparato material e de pessoal maior por parte do Estado, além de uma maior capacitação dos profissionais envolvidos no procedimento, posto que não adianta existir um direito, se quem aplica não compreende com profundidade o que ele significa e qual a razão dele precisar ser resguardado.

O que se busca não é algo impraticável ou extraordinário, levar o acusado a presença de um juiz e outras autoridades pouco tempo depois de sua prisão, deve ser encarada como a oportunidade de uma prestação célere e capaz de otimizar uma resposta jurisdicional. 
Fato é, que a Audiência de Custódia é defendida veementemente por instituições sérias e garantistas, como o Conselho Nacional de Justiça, Ordem dos Advogados do Brasil e a Defensoria Pública Estadual. A atuação dessas instituições, no mínimo, demonstra que o assunto é de relevância e merece atenção.

Organismos internacionais de amparo aos direitos humanos também apontam a necessidade da existência da Audiência de Custódia, inclusive proferindo decisões que censuram países violadores desse direito, como pôde ser observado nas decisões colacionadas nesse trabalho

Aparentemente, muitos esquecem que ser acusado é bastante diferente de ser condenado, no qual princípios como da inocência ou não culpabilidade parece dar lugar à presunção de culpabilidade. Encarcerar acusados no Brasil, mesmo que provisoriamente, é em verdade, fazê-los experimentar uma condenação que não se sabe se virá ou mesmo quando virá. Àquelas pessoas presas, condenadas ou não, culpadas ou não, um dia deixarão o cárcere e carregarão consigo toda a experiência de descaso vivida.

Essas pessoas devem prestar contas com o Estado e a sociedade caso sejam condenados, mas enquanto isso, cabe ao Estado reconhecer sua presunção de inocência e tentar minimizar as muitas injustiças que são experimentadas nas prisões desse país.

Nesses moldes, a pesquisa confirma a hipótese anteriormente proposta, chegando-se ao resultado de que a Audiência de Custódia é sim um direito humano fundamental que vem sendo omitido pelo Estado Brasileiro, e é uma possibilidade real de combate à superlotação carcerária, de resguardo da dignidade da pessoa humana, de prevenção e identificação de práticas de tortura e de atuação interdisciplinar, e que inegavelmente, proporciona um maior amparo à pessoa detida. E por fim, sendo a Audiência de Custódia mais uma tentativa de resguardo dos já tão violados direitos dos presos, que ela seja bem vinda.

\section{REFERÊNCIAS}

BARBOSA, Ruchester Marreiro. Audiência de Custódia e o Sistema de Dupla Cautelaridade como Direito Humano Fundamental: Uma análise contextualizada com a criminologia, ciência política e sociologia, com estudo aprofundado de casos já julgados pela Corte Interamericana de Direitos Humanos sobre a audiência de custódia. Disponível em: http://ruchesterbarbosa.jusbrasil.com.br/artigos/173154765/audiencia-de-custodia-e-osistema-da-dupla-cautelaridade-como-direito-humano-fundamental. Acesso em: $08 \mathrm{de}$ abr. de 2015. 
BRASIL. Código de Processo Penal Brasileiro. Disponível em: http://www.planalto.gov.br/ccivil_03/decreto-lei/del3689compilado.htm. Acesso em: 05 de maio de 2015.

Projeto de Lei do Senado $n^{\circ}$ 554/2011. Disponível em: http://www.senado.gov.br/atividade/materia/detalhes.asp?p_cod_mate=102115. Acesso em: 12 de maio de 2015.

- Conselho Nacional de Justiça. Audiência de Custódia. Disponível em: http://www.cnj.jus.br/sistema-carcerario-e-execucao-penal/audiencia-de-custodia. Acesso em: 18 de maio de 2015.

. Supremo Tribunal Federal. Ação Direta de Inconstitucionalidade $\mathbf{n}^{\circ}$ 5.240/2015/SP. Relator Ministro Luiz Fux. Disponível em: http://www.stf.jus.br/ portal/processo/verProcessoAndamento.asp?incidente=4711319. Acesso em: 22 de julho de 2015 .

Supremo Tribunal Federal. Recurso Extraordinário n ${ }^{\circ}$ 466.343/SP. Relator Min. Cezar Peluso (22.11.2006). Disponível em: http://www.stf.jus.br/portal/ processo/ver ProcessoTexto.asp?id=2330845\&tipoApp=RTF. Acesso em: 18 de maio de 2015.

CASSIOLATO, Bruno Luiz. Considerações sobre audiência de custódia: pontos positivos e negativos. Disponível em: http://www.apamagis.com.br/website/Ler. php?type=1\&id $=33994$. Acesso em: 10 de abr. de 2015.

CHOUKR, Fauzi. A denominada "audiência de custódia": PL 554/2011. A necessária (e lenta) adaptação do processo penal brasileiro à Convenção Americana de Direitos do Homem. Disponível em: http://fhchoukr.jusbrasil.com.br/artigos/161820782/a-denominadaaudiencia-de custodia. Acesso em: 08 de abr. de 2015.

Convenção Americana de Direitos Humanos. Disponível em: http://www.cidh.oas.org/ basicos/portugues/c.Convencao_Americana.htm. Acesso em: 09 de abr. de 2015.

CORTE INTERAMERICANA DE DIREITOS HUMANOS. Sentencia de $\mathbf{2 4}$ de junio de 2014 - Caso Acosta Calderón Vs. Ecuador. Disponível em: http://www.corteidh.or.cr/docs/casos/articulos/seriec_129_esp1.pdf. Acesso em: 25 de maio de 2015.

Sentencia de 30 de octubre de 2008 - Caso Bayarri vs. Argentina. Disponível em: http://www.corteidh.or.cr/docs/casos/articulos/seriec_187_esp.doc. Acesso em: 25 de maio de 2015. 
GOMES, Luiz Flávio; MAZZUOLI, Valerio de Oliveira. Comentários à Convenção Americana sobre Direitos Humanos: Pacto de São José da Costa Rica. 3 ed. ver. e amp. São Paulo: Editora Revista dos Tribunais, 2010. Coleção Ciências Criminais. Coordenação Luís Flávio Gomes e Rogério Sanches Cunha.

FERREIRA FILHO, Manoel Gonçalves. Direitos Humanos Fundamentais. $10^{\mathrm{a}}$ ed. São Paulo: Saraiva, 2008. p. 100.

LOPES JR., Aury; PAIVA, Caio; Audiência de Custódia aponta para evolução civilizatória do processo penal. Revista de Liberdade $\mathrm{n}^{\circ} 17$ - setembro/dezembro de 2014 . ISSN 2175-5280. Publicação do Instituto Brasileiro de Ciências Criminais. Disponível em: http://www.revistaliberdades.org.br/site/outrasEdicoes/outrasEdicoes Exibir.php?rcon_id=209 . Acesso em: 09 de abr. de 2015.

LOPES JR., Aury; ROSA, Alexandre Morais. Afinal, quem tem medo da audiência de custódia (parte1). Disponível em: http://www.conjur.com.br/2015-fev-13/limite-penalafinal-quem-medo-audiencia-custodia-parte. Acesso em: 12 de maio de 2015.

NUCCI, Guilherme de Sousa. Os mitos da Audiência de Custódia. Disponível em: http://www.guilhermenucci.com.br/artigos/guilherme-nucci/processo-penal/os-mitos-daaudiencia-de-custodia-2. Acesso em: 21 de julho de 2015.

Pacto Internacional de Direitos Civis e Políticos. Disponível em: http://www.planalto. gov.br/ccivil 03/decreto/1990-1994/D0592.htm. Acesso em 10 de ab. de 2015.

PIAUÍ. Diário Oficial do Estado do Piauí de 23 de junho de 2015. Disponível em: http://www.diariooficial.pi. gov.br/diario/201506/DIARIO23_ela4309df1.pdf. Acesso em: 27 de julho de 2015.

Diário Oficial de Justiça do Estado do Piauí de 21 de julho de 2015. Disponível em: http://www.tjpi. jus.br/site/uploads/diario/dj150721.pdf. Acesso em: 27 de julho de 2015.

PIOVESAN. Direitos Humanos e o Direito Constitucional Internacional. 13 ed. São Paulo: Saraiva, 2012.

SIQUEIRA JR., Paulo Hamilton; OLIVEIRA, Miguel Augusto Machado. Direitos Humanos e Cidadania. $3^{\circ}$ ed. ver. e amp. São Paulo: Editora Revista dos Tribunais, 2010.

STRECK, Lenio Luiz; MORAIS, José Luiz Bolzan de. Ciência Política e Teoria do Estado. 7 ed. 2. tir. Porto Alegre: Livraria do Advogado Editora, 2012. 